Review

\title{
Antibody Fragments as Probe in Biosensor Development
}

\author{
Dirk Saerens $^{1,2, *}$, Lieven Huang ${ }^{1,2,3,4}$, Kristien Bonroy ${ }^{5}$ and Serge Muyldermans ${ }^{1,2}$
}

1 Laboratory of Cellular and Molecular Immunology, Vrije Universiteit Brussel, Pleinlaan 2, B-1050 Brussels, Belgium

2 Department of Molecular and Cellular Interactions, VIB, Brussels, Belgium

3 Department of Molecular Biology, Technologiepark 927, B-9052 Zwijnaarde, Ghent University, Ghent, Belgium

4 Department for Molecular Biomedical Research, VIB, Ghent, Belgium

5 IMEC, NEXT, Kapeldreef 75, B-3001 Leuven, Belgium

* Author to whom correspondence should be addressed; E-mail: dsaerens@vub.ac.be

Received: 7 July 2008; in revised form: 6 August 2008 / Accepted: 7 August 2008 /

Published: 8 August 2008

\begin{abstract}
Today's proteomic analyses are generating increasing numbers of biomarkers, making it essential to possess highly specific probes able to recognize those targets. Antibodies are considered to be the first choice as molecular recognition units due to their target specificity and affinity, which make them excellent probes in biosensor development. However several problems such as difficult directional immobilization, unstable behavior, loss of specificity and steric hindrance, may arise from using these large molecules. Luckily, protein engineering techniques offer designed antibody formats suitable for biomarker analysis. Minimization strategies of antibodies into Fab fragments, scFv or even single-domain antibody fragments like VH, VL or VHHs are reviewed. Not only the size of the probe but also other issues like choice of immobilization tag, type of solid support and probe stability are of critical importance in assay development for biosensing. In this respect, multiple approaches to specifically orient and couple antibody fragments in a generic one-step procedure directly on a biosensor substrate are discussed.
\end{abstract}

Keywords: display technology, affinity, stability, immobilization, immunoassay. 


\section{Antibodies in sensor applications}

Over the past few years, multiple protein biomarkers have been suggested as a diagnostic target based on genomic or proteomic studies. Devices such as biosensors that could measure those biomarkers rapidly (e.g. within 10 minutes) and at very low concentrations (e.g. at fg/ml) would be advantageous in diagnostic development. In particular, the capacity of the biosensor to meet challenges such as sensitive detection and low-level quantification of analytes, will undoubtedly put them more in the spotlight ${ }^{1}$. Biosensors are built up of a biological target-recognition element that is connected to a transduction element using a suitable interface layer. Binding events occurring at this functionalized interface layer are translated by the transducer into a comprehensive read-out ${ }^{2}$. These biosensors provide a rapid, convenient, low cost alternative to conventional analytical methods such as HPLC, ELISA, 2-D gel electrophoresis or mass-spectrometry, for detecting or assaying a biomarker.

One particular category of biosensors is the antibody-based biosensor or immunosensor. This type of biosensor relies on the ability of an immobilized antibody $(\mathrm{Ab})$ to recognize its associated target, known as antigen (Ag). For biosensor development these Ab-based probes should meet very high standards such as high specificity in a very complex medium, well-characterized binding properties, high stability and the possibility of large-scale production preferably at low cost ${ }^{3}$. Another important aspect in biosensor design is the quality of the interface layer between probe and transduction element since it will also determine both the sensitivity and the specificity of the biosensor. Here several problems may arise, as proteins and Abs in general are chemically and structurally complex and heterogeneous. This makes them often unpredictable regarding their interactions with the biosensor substrate ${ }^{4}$. Therefore, it is difficult to define a general protein detection and immobilization strategy ${ }^{5}$.

Immunoassays based on polyclonal $(\mathrm{pAb})$ and monoclonal $(\mathrm{mAb})$ antibodies have been around for more than 30 years and are still among the most important diagnostic tools widely used in clinical and research areas ${ }^{6}$. The pAbs can easily be generated, but batch-related differences, varying affinity and poly-specificity (i.e. reactivity with more than one target) can create serious problems, certainly when used as a probe in biosensors ${ }^{7}$. In contrast, a mAb can be selected to be more specific for a unique epitope present on the protein of interest and/or its variant(s). In addition, any particular mAb can - in principle - be obtained reproducibly in unlimited quantities and its target-affinity can at least be determined. Their identification is amenable to a high-throughput mode by immunizing animals with antigen mixtures followed by automated screening so that large numbers of additional binders per annum are within reach. Moreover, many mAbs are already used as affinity reagents for identification, validation, quantification, localization, functional analysis and ablation of proteins ${ }^{8}$.

Nowadays, these Abs are proposed as prime candidates to be used as probes in biosensors. Despite some successes, a reasonable fraction of the mAbs selected for specific analyte recognition fails to function properly in the biosensor setup due to unpredictable conformation changes on surfaces, or unwanted reactivities mediated by their Fc part. Therefore Abs have previously been minimized into different $\mathrm{Ab}$ formats and optimized for affinity and/or stability to improve development of a robust Abbased probe for biosensor applications ${ }^{9}$. In addition, it has become obvious that immobilization engineering is a mandatory step in the development ${ }^{10}$. In many cases loss of biological activity upon immobilization of Abs is noticeable. One reason might be the random orientation of the Abs on sensor surfaces whereby optimal $\mathrm{Ag}$ binding is prohibited compared to soluble $\mathrm{Abs}^{11}$. 


\section{Available antibody fragment formats}

Since the introduction of recombinant $\mathrm{Ab}$ engineering, the size of $\mathrm{mAbs}$ has been minimized and adapted into different formats suitable for the envisaged application ${ }^{8}$. The well-established smaller engineered format of a mAb is the Fab fragment containing the complete Light-chain (VL and CL domain) and the first half of the Heavy-chain, the Fd (VH and $\mathrm{CH} 1$ domain) (Figure 1A). The Fab encompasses the Ag-binding domain without the effector function fragment, the Fc part. Even smaller fragments can be designed from the Fab fragment, e.g. an Fv and the single-chain Fv (scFv) fragment ${ }^{12}$.

With a small flexible polypeptide linker between $\mathrm{VH}$ and $\mathrm{VL}$ domain, the $\mathrm{scFv}$ fragment is generally more stable than the Fv fragment, which leads to higher functionality ${ }^{13}$. Unfortunately, this synthetic linker causes dimerization and aggregation of the $\mathrm{scFv}$, subsequently fuelling many investigations into more stable Ag-binding $\mathrm{Ab}$ fragments ${ }^{14}$, e.g. the $\mathrm{scFab}^{13}$. The smallest possible Agbinding $\mathrm{Ab}$ fragment from a mAb is made up of just one variable domain, e.g. the $\mathrm{VH}$ or $\mathrm{VL}^{14}$. Unfortunately these fragments have a pronounced tendency to form aggregates as these isolated singledomains often expose large hydrophobic regions to the solvent.

Figure 1. Ab fragments from conventional (A), Heavy-chain (B) and cartilaginous fish (C).
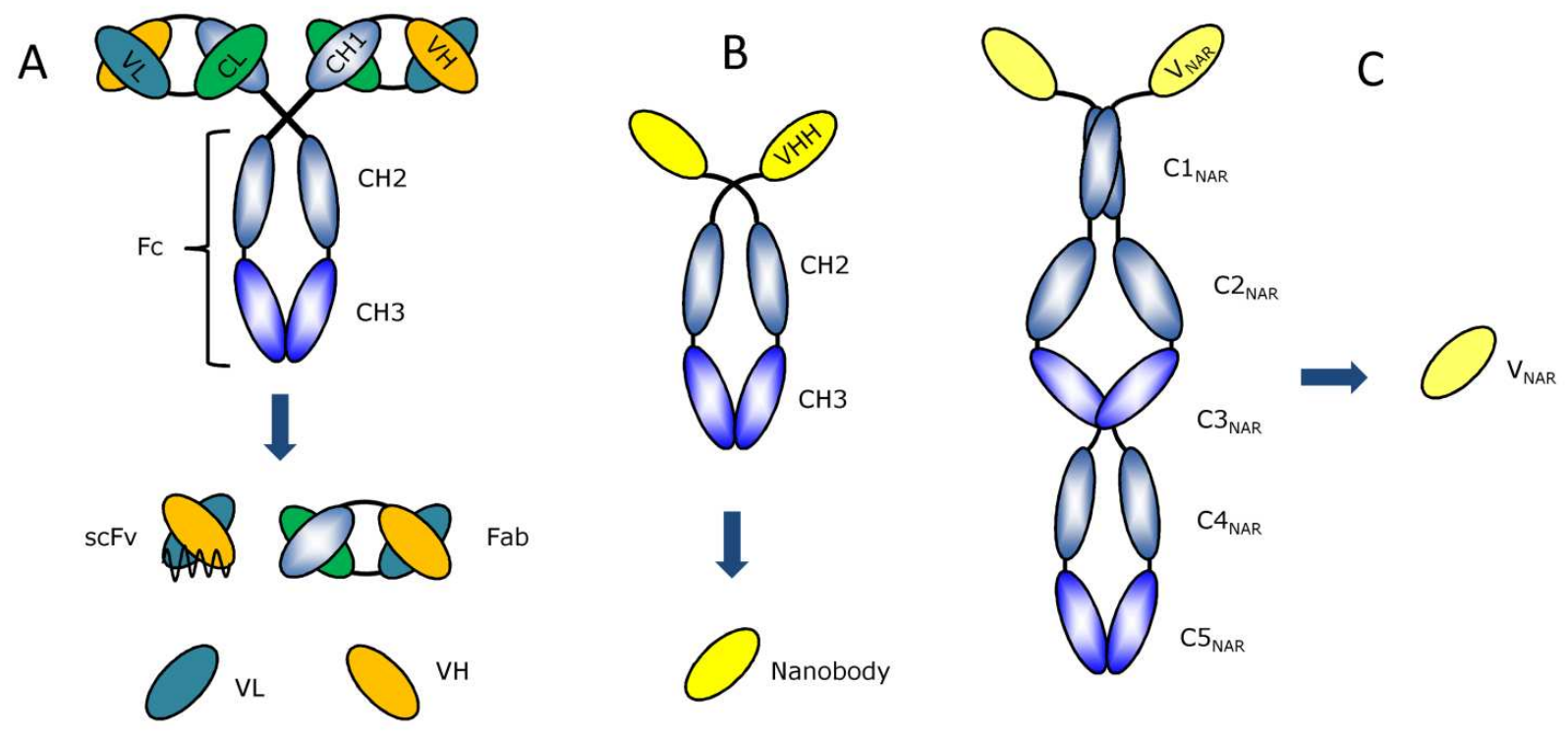

Antibodies have dogmatically been described as being composed invariably of two identical Heavychains and two identical Light-chains. The species of the Camelidae (i.e. Camelus dromedarius, $C$. bactrianus, Lama glama, L. guanoco, L. alpaca and L. vicugna) however produce a surprising exception to this paradigm. Their serum contains a considerable fraction of Heavy-chain Abs (HCAbs), that lack the Light-chain ${ }^{15}$ (Figure 1B). The Heavy-chain within the HCAbs is composed of three instead of four globular domains. The two constant domains are highly homologous to the $\mathrm{CH} 2-\mathrm{CH} 3$, $\mathrm{Fc}$ domains of classical $\mathrm{Abs}^{16}$. Remarkably, the domain corresponding to the $\mathrm{CH} 1$ domain of classical Abs is missing in HCAbs. Hence, the Ag-binding fragment of a classical Ab, the Fab, is reduced to a single variable domain in the HCAb. This variable domain referred to as $\mathrm{VHH}^{17}$ or Nanobody ${ }^{18}$ is adapted to become functional in Ag-binding in absence of a variable Light-chain domain (VL) ${ }^{19}$. It has 
been repeatedly demonstrated that the $\mathrm{VHH}$, cloned and expressed in bacteria, is a strictly monomeric, single-domain Ag-binding entity ${ }^{20}$. Even more recently, an alternative natural single domain antibody format was discovered in cartilaginous fish, e.g. sharks. A new and probably ancestral immunoglobulin isotype termed "novel antigen receptor" (Ig-NAR) was described ${ }^{21}$. Similar to HCAbs in camelids, this new isotype is a Heavy-chain homodimer. The Ig-NAR is a disulfide bonded homodimer of two identical H-chains that lacks light chains. Each H-chain contains one variable domain (V-NAR) and five constant domains (Figure 1C).

The reduced size, improved solubility and higher stability of the camelid Heavy-chain and shark IgNAR antibody fragments are of special interest for biotechnological and medical applications, including biosensors ${ }^{22}$.

\section{Generation of antibody fragments libraries}

Recombinant $\mathrm{Ab}$ technologies to engineer $\mathrm{mAbs}$ into smaller $\mathrm{Ab}$ fragments, although very promising, may cause loss of affinity, increased tendency to aggregate, increased temperature sensitivity, and low yield of protein functional in $\mathrm{Ag}$ recognition. Moreover the isolation and subsequent purification of mAbs is a very costly and time-consuming process. These issues can be circumvented by selecting Ag-binding $\mathrm{Ab}$ fragments from libraries using in vitro screening technologies and bacterial expression of the selected clone. This construction of highly diverse expression libraries of Ag-binding $\mathrm{Ab}$ fragments based on combinatorial principles is the first key technology en route to obtain optimal Ab-based probes. An Ab fragment library is usually derived from a single scaffold such as Fab, scFv or VH. Essentially, variability is generated at several regions of the Ag-binding moiety in many different ways; from the random combination of VH and VL domains, to the introduction of variability into the antibody scaffold using synthetic ${ }^{23 ;} 24$ or semisynthetic ${ }^{25 ; 26}$ approaches. Several methods were already optimized and resulted in the construction of large scFv libraries $^{27 ; 28 ; 29}$. Such hyperdiversified Ab fragment libraries enabled the selection of Ab fragments specific to virtually any target. Besides these synthetic libraries, Ab fragments can be selected from a camelid non-immune library ${ }^{30}$ or immune libraries against a wide variety of antigens ${ }^{18 ; 31 ; 32 ; 33}$. Subsequent isolation of Ag-specific Ab fragments from these libraries can be performed via different screening techniques.

\section{Selection of antigen-specific antibody fragments}

In order to isolate highly potent Ab-based probes from these large libraries, so-called display technologies are the second key technology to identify probes. Display technologies physically link the probes' genotype with its phenotype, and allow very efficient handling of large expression libraries (sometimes encompassing $>10^{10}$ individual clones). Various forms of display technologies such as phage display $^{34 ; 35 ; 36}$, ribosome display ${ }^{37 ; 38 ; 39 ; 40}$ or mRNA display $^{41}$ libraries have been reported. Ribosomal display has the advantage that it does not require bacterial host cells, and thus there is nearly no limit in extension of library complexity. Here genotype and phenotype are linked through ribosomal complexes, consisting of mRNA lacking a stopcodon, ribosome and encoded protein that are used for selection. However due to the high technological demands of ribosome display, widespread application of this technology has been hampered. 
The most robust of these in vitro selection procedures - and by far the most widely used - is phage display. Phage display has been utilized for isolating recombinant Ab fragments. After construction of an $\mathrm{Ab}$ combinatorial library, Ag-specific recombinant $\mathrm{Ab}$ fragments can be easily isolated by biopanning of the phage library displaying $\mathrm{Ab}$ fragments fused with viral coat protein III against antigen proteins, antigen-expressing live cells, or fixed cells ${ }^{36}$. Several steps in Ab phage display may be improved by: (i) increasing the size of the library to enlarge the chances to select for high affinity binders within the repertoire, (ii) adapting the bio-panning procedure for isolation of $\mathrm{Ab}$ fragments reactive with immunological minor epitopes ${ }^{42}$, (iii) enhancing the expression level and stability of the selected $\mathrm{Ab}$ fragments and (iv) engineering of the expression phagemid cloning vector ${ }^{43}$.

Combining the $\mathrm{Ab}$ fragment libraries with powerful phage display has led to a multitude of generated $\mathrm{Ab}$ fragments. Although these various technologies allow the isolation of highly specific antibody fragments, these fragments do not necessarily meet the functional standards required for successful employment in a biosensor format. These problems can be overcome by use of optimized scaffolds ${ }^{44}$ or stress driven selections (e.g. temperature ${ }^{45}$ or chemical denaturing ${ }^{32}$ ). Once a suitable $\mathrm{Ab}$ fragment has been selected to bind a diagnostically relevant epitope, further engineering can be performed to increase antigen affinity, probe stability or immobilization potential. Different approaches to further improve the Ab properties towards ideal biosensor probes are described below.

\section{Affinity engineering}

High-affinity is a prerequisite for the development of simple and highly sensitive biosensors. Sometimes the $\mathrm{Ab}$ fragments selected via display technologies fail to meet the required kinetic-affinity parameters of target association/dissociation to develop an optimal sensor assay. Ideally, the $\mathrm{k}_{\text {on }}$ value (i.e. the kinetic association rate) needs to be above $10^{5} \mathrm{M}^{-1} \mathrm{~s}^{-1}$ for rapid assay results (less than 15 minutes). The $\mathrm{k}_{\text {off }}$ value (i.e. kinetic dissociation rate) seems to be less critical, and values from $10^{-3} \mathrm{~s}^{-1}$ are appropriate for acceptable target release. Panning of immune libraries usually yields Ab fragments that bind with nanomolar affinity $\left(\mathrm{K}_{\mathrm{D}}=\mathrm{k}_{\mathrm{off}} / \mathrm{k}_{\text {on }}\right)$ to their cognate target. However, binders retrieved after panning of (semi-) synthetic libraries do not routinely reach such low $K_{D}$ values. The improvement of affinity of an $\mathrm{Ag}-\mathrm{Ab}$ interaction, although challenging, can be tremendous beneficial to develop a sensitive biosensor. Several techniques such as random mutagenesis, direct evolution, ribosome display, etc. can be included to optimize the $\mathrm{Ab}$ fragments towards a more suitable $\mathrm{k}_{\text {on }}$ or $\mathrm{k}_{\text {off }}$ value. Affinity maturation via a combination of molecular evolution and high-throughput methods (e.g. via ribosome display) is preferred. This combination has resulted in the isolation of specific antibody fragments from naïve libraries, with sufficient affinity for analyte biosensing applications ${ }^{46}$.

\section{Stability engineering}

An overlooked parameter of $\mathrm{Ab}$ fragments for immunosensor development is the intrinsic stability. Not only is long-term storage and re-usability of Ab chips important from a practical point of view, but also stability during manufacturing it is a critical factor. Therefore high demands are placed on the functional stability of the probes for biosensors.

The Fv and scFv fragments engineered from mAbs or selected from combinatorial libraries do not always reach the required stability treshold ${ }^{47}$. U . Upon construction of $\mathrm{FV}$ and scFv fragments, the 
variable domains are removed from their natural Fab context, where they are associated with the constant domains of the Light-chain (CL) and Heavy-chain (CH1). Despite mutual stabilization of the domains in a scFv, most $\mathrm{scFv}$ derived from mAbs show poor to moderate stability without additional engineering $^{12}$. Many research groups have solved the problem of the limited stability of the Fv Ab fragment via different routes. Both VL and VH domains can be fused into many alternative formats, besides the conventional scFv format. In a first format the $\mathrm{CH} 1$ and $\mathrm{CL}$ domain of the Fab fragment are replaced with a heterodimeric coiled coil, resulting in a helix-stabilized $\mathrm{Fv}$ fragment $(\mathrm{hsFv})^{49}$. In a second format, the disulfide-stabilized $\mathrm{Fv}$ fragment (dsFv), a cysteine residue is introduced into the conserved framework regions of both the $\mathrm{VH}$ and $\mathrm{VL}$ at positions compatible with the formation of an interdomain disulfide linkage. This $\mathrm{dsFv}$ can bind antigen with identical affinity, and proved to be substantially more resistant to heat or urea treatment than the $\mathrm{scFv}^{50}$. Another format to stabilize the $\mathrm{scFv}$ is obtained by introducing a disulfide bond into the $\mathrm{scFv}$ which results in a ds-scFv, combining the stability of the disulfide form with the expression advantages of the $\mathrm{scFv}^{51}$. The reformatting of the $\mathrm{scFv}$ into a Fab fragment is an alternative strategy that leads towards an improved functional stability of the Ab fragment. Such approach might - in some cases - replace the additional maturation steps, when the affinity and stability are close to the limit of tolerance for a successful biosensor assay ${ }^{52}$. However, it is rather preferred to minimize the dimensions of the antibody-based probes to get a maximal amount of probe onto the sensor surface, than enlarging the probe into a Fab.

Besides applying optimized formats, the variable domains of suboptimal stability can be engineered for improved robustness and folding efficiency while preserving their Ag-binding specificity and affinity. This can be performed either by introducing a limited number of point mutations ${ }^{53}$ or by grafting their Ag-specificity onto variable domains with frameworks of superior stability. The grafting technique, originally utilized to humanize Abs, involves loop grafting of the CDR-loops of less-stable $\mathrm{Ab}$ fragments onto a highly stable framework, resulting in a reshaped $\mathrm{Ab}$ fragment with the $\mathrm{Ag}$ specificity of the donor $\mathrm{Ab}$ and the stability of the acceptor framework ${ }^{25}$. Grafting onto $\mathrm{scFv}$ was shown on multiple occasions ${ }^{54 ;}$. In case of camelid Heavy-chain Ab fragments similar results were obtained, i.e. a universal loop acceptor VHH-scaffold was identified and revealed to be able to harbor loops from different VHHs. This allows stabilization of Nanobodies for employment as probes in biosensors or microarrays ${ }^{56}$. Recently, a novel method for increasing the intrinsic stability of $\mathrm{Ab}$ fragments was proposed. By inserting a disulfide bond in the hydrophobic core of any variable $\mathrm{Ab}$ domain, the chemical and thermal stability could be increased ${ }^{57 ; 58}$.

The above mentioned techniques are used when the Ab-based probe is already available and stability improvement is required. To increase the level of throughput in Ab-based probe generation, combinatorial libraries can be used in conjunction with stress-guided selection techniques. This resulted already in several general strategies for probe generation ${ }^{59 ; 60 ; 61}$.

The $\mathrm{Ab}$ intrinsic stability is important during probe regeneration. Biosensor applications involving multiple detection cycles are critically dependent on the feasibility to fully regenerate the probe, i.e. the complete removal of captured analyte from the probe in between two detection cycles. Such regenerations might create an additional difficulty when the cleaning conditions destroy the activity of the probe. It becomes even more difficult for probe-analyte complexes with high affinity constants. These will require extreme conditions to disrupt their interaction. Backmann et al. ${ }^{47}$ reported on a 
label free immunosensor using single-chain antibody fragments where repeated regeneration with low$\mathrm{pH}$ buffer resulted in loss of binding activity. This indicated that the covalent immobilized scFv fragments might undergo unfolding and denaturation upon harsh regeneration. Since intrinsic stability of the probe has been shown to be an important parameter for optimal biosensor design ${ }^{62}$, problems with regeneration can be circumvented by selecting Ab-based probes with high intrinsic stability.

\section{Immobilization of antibody fragments}

The attachment of active recognition molecules at high-density to the transducer surface is one of the most critical steps in biosensor development. Proper strategies for Ab immobilization will mainly be determined by the solid sensing substrate and the properties of the interface layer. The most suitable method of $\mathrm{Ab}$ immobilization therefore varies with the type of biosensor that needs to be coated with the desired probe. The full-sized Ab has estimated molecular dimensions of $15 \times 7 \times 3.5 \mathrm{~nm}^{10}$, whereas the smallest $\mathrm{Ab}$ fragments, i.e. single-domain Ab fragments, are only 4 × 2.5 x $3.5 \mathrm{~nm}$. Moreover, the $\mathrm{Ab}-\mathrm{Ag}$ interaction is also affected by the nature of the interface layer between the immobilized $\mathrm{Ab}$ and the sensor surface ${ }^{63}$. Ideally, the probe should specifically recognize and bind its antigen at the lowest possible concentration. Since the biosensor surfaces are in the $\mu \mathrm{m}$ scale, the smaller the Ab fragment, the more probes can be immobilized onto the surface, resulting in an enhanced detection sensitivity ${ }^{64}$. Unfortunately it has been observed regularly that proteins, and Abs in particular, may lose (part of) their biological activity when immobilized on a surface. This can be attributed to a combination of two factors: change in conformation upon cross-linking and/or unfavorable orientation of the probes $^{65}$ (Figure 2A).

Physical adsorption is the simplest process of protein binding, although rather uncontrollable. It occurs through hydrophilic, hydrophobic or both types of interactions between Abs and the sensor surface. Random orientation of the absorbed Abs and close proximity between adsorptive surface and the Ag-binding site could impede the detection (Table 1).

Covalent attachment of Abs on chemically-activated sensor surfaces is the most common method for $\mathrm{Ab}$ immobilization. Numerous chemical coupling reagents (e.g. glutaraldehyde, carbodiimide or succinimide ester) to cross-link mainly carboxylated functional groups have been tested to immobilize Abs onto various solid surfaces. Most commonly used covalent immobilization approaches couple the Abs randomly via their free amino-groups to the chemically-activated sensor surface. Such covalent binding of proteins to a biosensor surface represents a rational and robust approach (Table 1).

However, numerous studies over the past 40 years have shown that the physical adsorption or the covalent attachment procedures of antibodies onto solid supports increase the probability of denaturation or conformational change (Table 1). After surface immobilization, mAbs and recombinant $\mathrm{Ab}$ fragments exhibit non-uniform kinetic and thermodynamic properties with the respective Ag. A general solution is to uniformly orient the probes and increase the accessibility of their Ag-binding domains ${ }^{66}$ (Figure 2B).

Overall, the directional immobilization processes share several advantages. Usually, the Ag-binding domains of the probe are better accessible to the analyte when the surface-coupling site within the probe is at a distant position from the Ag-capturing site. Within the Ab population, the Ag-binding kinetics upon covalent immobilization remains more uniform and this can affect the biosensor 
sensitivity positively ${ }^{67}$. This was emphasized by Bonroy et al. ${ }^{68}$ when they showed for a particular AbAg pair that the optimized fragmentation protocol in combination with an oriented immobilization of Fab fragments on mixed self-assembled monolayers (SAMs) led to a more than two-fold increase of the Ag binding signals compared to randomly covalent immobilized full-length Abs.

Table 1. Advantages and disadvantages of different $\mathrm{Ab}$ fragment immobilization methods.

\begin{tabular}{|c|c|c|}
\hline Immobilization method & Advantages & Disadvantages \\
\hline \multirow[t]{4}{*}{ Adsorption } & Minimal manipulation & Random orientation \\
\hline & No Ab modification & Ab denaturation \\
\hline & Mostly high immobilization level & Non-specific protein binding \\
\hline & & Leakage of $\mathrm{Ab}$ from surface \\
\hline \multirow[t]{2}{*}{ Covalent coupling } & Stable immobilization & Random orientation \\
\hline & Commercially available surfaces & Ab modification, possible denaturation \\
\hline \multirow[t]{2}{*}{$\mathrm{Ab}$ fragment tag } & Oriented immobilization & Surface stability \\
\hline & Mild incubation & \\
\hline \multirow[t]{3}{*}{ Ab-binding proteins } & Oriented immobilization & Surface stability \\
\hline & No Ab modification & \\
\hline & Mild incubation & \\
\hline \multirow[t]{2}{*}{$\mathrm{Ab}$ fragment fusions } & Oriented immobilization & Compatibility between $\mathrm{Ab}$ fragment and \\
\hline & Surface stability & fusion partner \\
\hline
\end{tabular}

Figure 2. Ab fragment immobilization via random (A) or oriented (B) covalent coupling.

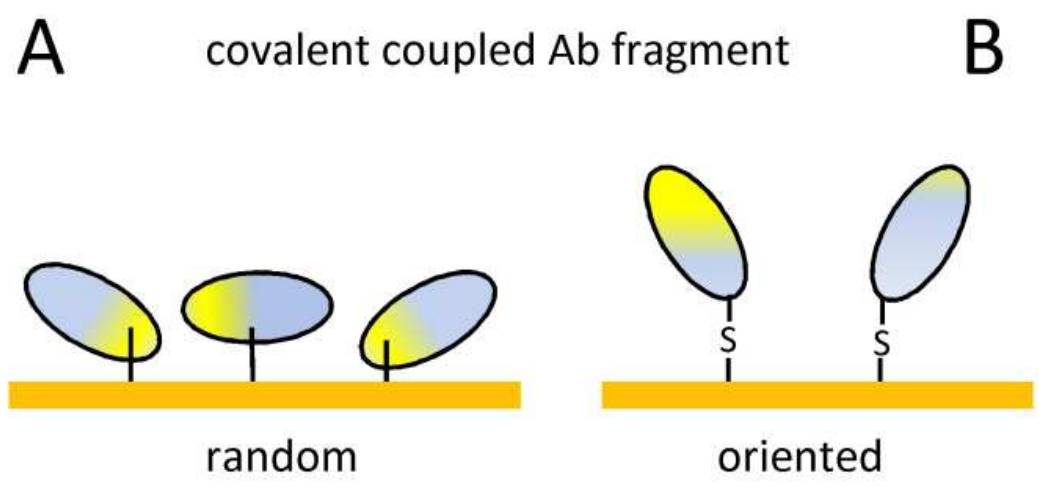

There are different approaches to obtain oriented immobilization of the probes. A first simple immobilization strategy involves the direct chemical coupling of the probe onto the transducer, e.g. a non-coated gold surface and available $-\mathrm{SH}$ groups on the probe ${ }^{69}$. Another methods uses a variety of 
chemical reactions to attach the probe via the $-\mathrm{SH}$ group to the gold substrate that is coated with a dextran layer $^{70}$ or sensor or with self-assembled monolayers (SAMs) of thiols ${ }^{2}$ (Figure 2B). Ab fragments such as a Fab fragment, could be immobilized via the native thiol group more easily after reduction of the $\mathrm{Fab}_{2}$ fragment ${ }^{71}$. Even an engineered $\mathrm{C}$-terminal cysteine residue at the light chain constant domain of a scFv fragment could be successfully applied to attach the probe via a heterobifunctional linker onto a gold surface ${ }^{72}$.

As an alternative to direct chemical coupling, oriented immobilization can also be achieved indirectly, via an intermediate layer (the so-called 'immobilization layer'), which is added between the gold thin-film and the immobilized $\mathrm{Ab}$. An elegant example is by utilizing natural $\mathrm{Ab}$ binding proteins such as protein $A$ or $G$ for increasing biosensor sensitivity and specificity ${ }^{73}$. Ab-binding proteins such as protein $A$ and $G$ have been extensively employed to capture Abs on biosensor surfaces with their Ag-binding site maximally exposed to the solution and thus remaining fully functional ${ }^{4}$ (Figure 3 ).

Figure 3. Ab fragment immobilization via intermediate layer.

\section{Ab fragment}

\section{Ab fragment binding protein, e.g. protein $A$}

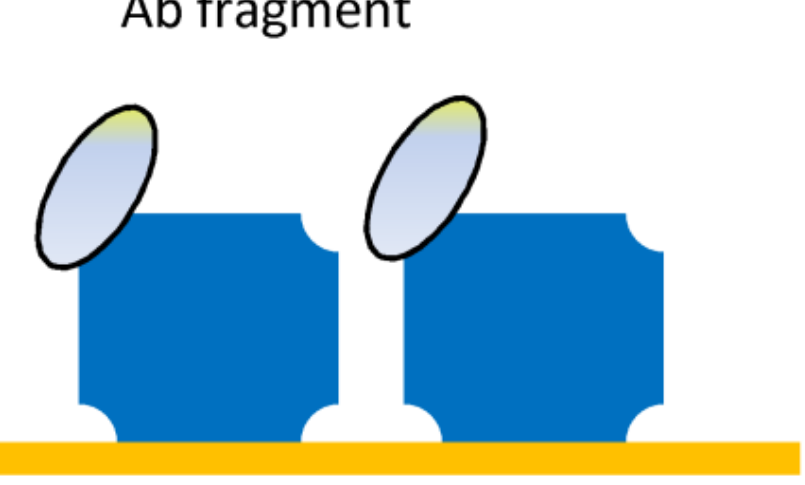

Another method for orienting Abs specifically onto surfaces consists of attachment of biotinylated Abs onto a (strept)avidin-modified surface (Figure 4). Ab fragments can be biotinylated by random or oriented labeling procedures. Random biotinylated scFvs can be coated onto surfaces at much higher densities than most commonly used Abs, improving the biosensor sensitivity and specificity ${ }^{74}$. Sitedirected biotinylation of Abs at their hinge region preferentially at the sulfhydryl groups between $\mathrm{CH} 1$ and CL domains was developed to immobilize Abs in an oriented manner via biotin-streptavidin linkage. These site-directed biotinylated Abs showed consistently enhanced detection capabilities compared to random biotinylated $\mathrm{Ab}$ preparations ${ }^{75}$. Site-specific biotinylation can also be obtained via a novel method for generation of yeast-secreted, in vivo biotinylated recombinant antibodies, or biobodies $^{76}$. The camelid single-domain antibody fragments can also be biotinylated in vivo at a sitespecific lysine residue within a designed tag and can thereafter be captured at high density in a directed orientation on a (strept)avidin coated biosensor substrate ${ }^{62}$. 
Figure 4. Ab fragment immobilization via biotin-(strept)avidin interaction.

biotinylated $\mathrm{Ab}$ fragment

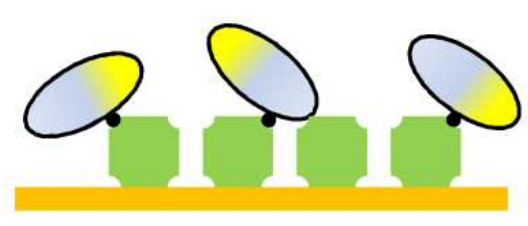

random

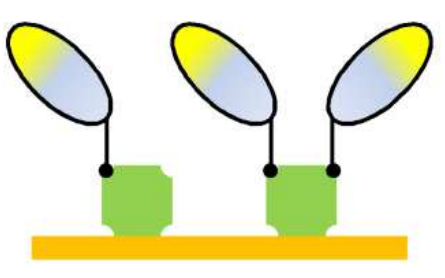

oriented

(strept)avidin

Recently $\mathrm{Ab}$ fragments were genetically fused to a range of proteins and subsequently immobilized onto the sensor surface. Fusion of the Ab fragments to a universal immobilization domain will provide identical orientation of all molecules (Figure 5). Pleschberger et al. ${ }^{77}$ succeeded in fusing a bacterial Slayer protein to a Nanobody. This fusion protein retained the ability to self-assemble onto solid surface into a square lattice structures with the Nanobody pointing outwards from the protein lattice surface into the solution. The monomolecular protein lattice could be exploited as a sensing layer in a biosensor setup. A similar approach was used for scFvs, whereby the fusion scFv with pIII surface protein allowed a more sensitive detection in their biosensor set-up ${ }^{78}$. Other chimeric proteins can be made via fusion of an $\mathrm{Ab}$ fragment with proteins such as beta-galactosidase, maltose-binding protein, calmodulin-binding protein, chitin-binding domain, cellulose-binding domain ${ }^{79}$ or glutathione-Stransferase.

Figure 5. Ab fragment immobilization via fusion partner.

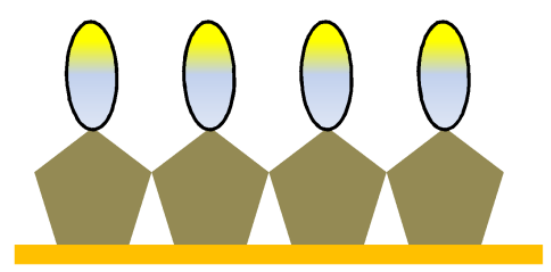

fusion partner, e.g. S-layer protein, maltose-binding protein, ...

Since most recombinant $\mathrm{Ab}$ fragments are expressed with an affinity tag in order to facilitate purification, this tag is also proposed for immobilization onto a sensor surface (Figure 6). His-tag fused $\mathrm{Ab}$ fragments could be non-covalently immobilized onto $\mathrm{Ni}^{2+}$ or gold surfaces. Several scFv fragments were engineered to contain two histidines within the linker peptide used to join the scFv heavy and light chains ${ }^{80}$. These scFvs bound to the surface in a proper orientation, retained antigen-binding affinity, and could be coupled at high surface concentrations. By replacing the standard single His ${ }_{6}$-tag

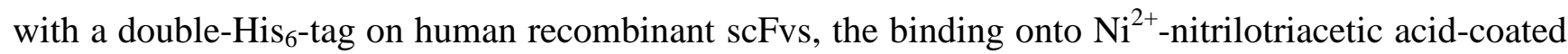
substrates was significantly enhanced ${ }^{81}$. These improved binding characteristics enabled non-purified probes as present in crude expression supernatants to be directly applied thereby eliminating the need for any time-consuming pre-purification step(s) prior to the probe immobilization. 
Figure 6. Ab fragment immobilization via affinity tag.

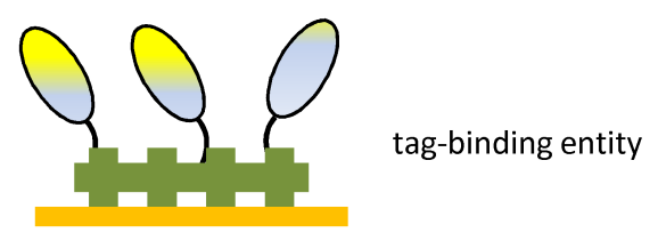

Moreover Abs with a high affinity for certain types of materials could be advantageous in biomaterial science and be used in an approach to immobilize probes on a biosensor device. Special selected or constructed $\mathrm{Ab}$ fragments with high affinity for certain materials can be used, e.g. an $\mathrm{Ab}$ fragment that binds to polyhydroxybutyrate, a biodegradable polymer that is often used as biomaterial, was generated by a phage display system. This $\mathrm{Ab}$ fragment could be used in bispecific constructs for site-directed oriented immobilization of $\mathrm{Ab}$ fragments on this biomaterial ${ }^{82}$ (Figure 7). In addition $\mathrm{Ab}$ fragments with binding affinity and specificity for non-biological inorganic material surfaces (e.g. gold) were generated by grafting material-binding peptides into loops of the complementarity determining regions of $\mathrm{Abs}^{83}$.

Figure 7. $\mathrm{Ab}$ fragment immobilization via bispecific construct containing a $\mathrm{Ab}$ fragment specific for the surface.

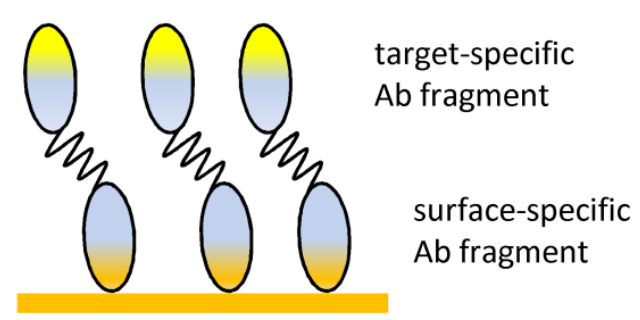

\section{Examples of antibody fragments in biosensor development}

Various studies on the use of antibody fragments as probes for biosensors were reported. For example Mechaly et al. ${ }^{84}$ developed a scFv fragment for the efficient and specific detection of $B$. anthracis spores, and demonstrated its successful application in detection platforms like ELISA, IFA and FCM. Hu et al. ${ }^{85}$ optimized a domoic acid-binding scFv antibody fragment and functionally immobilized it on a mesoporous silicate support for biosensor application development. Deng et al. ${ }^{86}$ isolated $\mathrm{scFv}$ fragments against Clostridium difficile toxin $\mathrm{B}$. This $\mathrm{scFv}$ could detect toxin $\mathrm{B}$ to a minimum of $10 \mathrm{ng}$ per well. These examples reveal how the recombinant antibody technology might assist in the rapid and effective development of next generation immunodiagnostic reagents. Huang et al. ${ }^{64}$ developed a human prostate-specific antigen (PSA) biosensor based on a camelid single-domain antibody fragments. Via covalent immobilization of the VHH onto mixed SAMs and an optimized sandwich assay, clinically relevant concentration of PSA could be measured. In related research, different VHH constructs were immobilized onto commercial and custom-built sensor surfaces by metal chelation, biotin-streptavidin interactions or covalent coupling ${ }^{62}$. For the first time, the intrinsic stability was presented as an important probe design factor, as higher intrinsic stability offers higher 
resistance to harsh environments. Finally, Carlsson et al. ${ }^{87}$ used large-scale recombinant scFv antibody microarrays for the first time to classify metastatic breast cancer versus healthy controls, based on differential protein expression profiling of whole serum samples. The miniature assay set-up provided $\mathrm{pM}$ range sensitivities and $>95 \%$ specificity.

\section{Concluding remarks}

A biosensor is envisaged as a compact, portable device which is (i) very useful in remote or developing regions without easy access to sophisticated laboratory facilities, (ii) amenable to mass production and (iii) minimized for development into a handheld, point-of-care-device ${ }^{88}$. Many biomarkers have been originally proposed as a direct result of -omics investigations. For their subsequent validation, it is essential to possess over highly specific probes that can detect those potential candidates. Antibodies are the natural molecules that fulfill the role of specific reporter molecules in vertebrates. In the post-genomic era and with high-throughput techniques available, the goal is to discriminate between all individual proteins from the proteome including their splice variants and post-translationally modified derivatives. Aided by advances in generation, selection and engineering of antibody-based recognition units, biosensors provide tools for improved diagnostics and biomarker discovery through detection of high- as well as low-abundant analytes even in complex, non-fractionated proteomes in conjunction with usage of small amounts of samples and reagents.

\section{Acknowledgements}

D.S. is Postdoctoral Fellow of the Research Foundation - Flanders (FWO). L.H. acknowledges financial support from the Instituut voor de aanmoediging van Innovatie door Wetenschap en Technologie in Vlaanderen (IWT-Vlaanderen) and the Emmanuel van der Schueren Stichting.

\section{References and Notes}

1. Holthoff, E.L.; Bright, F.V. Molecularly imprinted xerogels as platforms for sensing. Acc. Chem. Res. 2007, 40, 756-767.

2. Wink, T.; van Zuilen, S.J.; Bult, A; van Bennkom, W.P. Self-assembled monolayers for biosensors. Analyst 1997, 122, 43R-50R.

3. Holt, L.J.; Enever, C.; de Wildt, R.M.; Tomlinson, I.M. The use of recombinant antibodies in proteomics. Curr. Opin. Biotechnol. 2000, 11, 445-449.

4. Briand, E.; Salmain, M.; Compere, C.; Pradier, C.M. Immobilization of Protein A on SAMs for the elaboration of immunosensors. Colloids Surf. B. Biointerfaces 2006, 53, 215-224.

5. Pavlickova, P.; Schneider, E.M.; Hug, H. Advances in recombinant antibody microarrays. Clin. Chim. Acta 2004, 343, 17-35.

6. Nelson, P.N.; Reynolds, G.M.; Waldron, E.E.; Ward, E.; Giannopoulos, K.; Murray, P.G. Monoclonal antibodies. Mol. Pathol. 2000, 53, 111-117.

7. Ohara, R.; Knappik, A.; Shimada, K.; Frisch, C.; Ylera, F.; Koga, H. Antibodies for proteomic research: comparison of traditional immunization with recombinant antibody technology. Proteomics 2006, 6, 2638-2646. 
8. Hoogenboom, H.R. Selecting and screening recombinant antibody libraries. Nat. Biotechnol. 2005, 23, 1105-1116.

9. Haab, B.B.; Dunham, M.J.; Brown, P.O. Protein microarrays for highly parallel detection and quantitation of specific proteins and antibodies in complex solutions. Genome Biol. 2001, 2, research0004.1-research0004.13.

10. Jung, Y.; Jeong, J.Y.; Chung, B.H. Recent advances in immobilization methods of antibodies on solid supports. Analyst 2008, 133, 697-701.

11. Lu, B.; Smyth, M.R.; O'Kennedy, R. Oriented immobilization of antibodies and its applications in immunoassays and immunosensors. Analyst 1996, 121, 29R-32R.

12. Honegger, A. Engineering antibodies for stability and efficient folding. Handb. Exp. Pharmacol. 2008, 47-68.

13. Hust, M.; Jostock, T.; Menzel, C.; Voedisch, B.; Mohr, A.; Brenneis, M.; Kirsch, M.I.; Meier, D.; Dubel, S. Single chain Fab (scFab) fragment. BMC Biotechnol. 2007, 7, 14.

14. Holt, L.J.; Herring, C.; Jespers, L.S.; Woolven, B.P.; Tomlinson, I.M. Domain antibodies: proteins for therapy. Trends Biotechnol. 2003, 21, 484-490.

15. Hamers-Casterman, C.; Atarhouch, T.; Muyldermans, S.; Robinson, G.; Hamers, C.; Songa, E.B.; Bendahman, N.; Hamers, R. Naturally occurring antibodies devoid of light chains. Nature 1993, $363,446-448$.

16. Nguyen, V.K.; Hamers, R.; Wyns, L.; Muyldermans, S. Loss of splice consensus signal is responsible for the removal of the entire $\mathrm{C}(\mathrm{H}) 1$ domain of the functional camel IGG2A heavychain antibodies. Mol. Immunol. 1999, 36, 515-524.

17. Muyldermans, S. Single domain camel antibodies: current status. J. Biotechnol. 2001, 74, 277302.

18. Saerens, D.; Stijlemans, B.; Baral, T.N.; Nguyen Thi, G.T.; Wernery, U.; Magez, S.; De Baetselier, P.; Muyldermans, S.; Conrath, K. Parallel selection of multiple anti-infectome Nanobodies without access to purified antigens. J. Immunol. Methods 2008, 329, 138-150.

19. Muyldermans, S.; Atarhouch, T.; Saldanha, J.; Barbosa, J.A.; Hamers, R. Sequence and structure of VH domain from naturally occurring camel heavy chain immunoglobulins lacking light chains. Protein Eng. 1994, 7, 1129-1135.

20. Muyldermans, S.; Lauwereys, M. Unique single-domain antigen binding fragments derived from naturally occurring camel heavy-chain antibodies. J. Mol. Recognit. 1999, 12, 131-140.

21. Dooley, H.; Flajnik, M.F.; Porter, A.J. Selection and characterization of naturally occurring singledomain (IgNAR) antibody fragments from immunized sharks by phage display. Mol. Immunol. 2003, 40, 25-33.

22. Dumoulin, M.; Conrath, K.; Van Meirhaeghe, A.; Meersman, F.; Heremans, K.; Frenken, L.G.; Muyldermans, S.; Wyns, L.; Matagne, A. Single-domain antibody fragments with high conformational stability. Protein Sci. 2002, 11, 500-515.

23. Fellouse, F.A.; Esaki, K.; Birtalan, S.; Raptis, D.; Cancasci, V.J.; Koide, A.; Jhurani, P.; Vasser, M.; Wiesmann, C.; Kossiakoff, A.A.; Koide, S.; Sidhu, S.S. High-throughput generation of synthetic antibodies from highly functional minimalist phage-displayed libraries. J. Mol. Biol. 2007, 373, 924-940. 
24. Silacci, M.; Brack, S.; Schirru, G.; Marlind, J.; Ettorre, A.; Merlo, A.; Viti, F.; Neri, D. Design, construction, and characterization of a large synthetic human antibody phage display library. Proteomics 2005, 5, 2340-2350.

25. Desiderio, A.; Franconi, R.; Lopez, M.; Villani, M.E.; Viti, F.; Chiaraluce, R.; Consalvi, V.; Neri, D.; Benvenuto, E. A semi-synthetic repertoire of intrinsically stable antibody fragments derived from a single-framework scaffold. J. Mol. Biol. 2001, 310, 603-615.

26. Liu, J.L.; Anderson, G.P.; Goldman, E.R. Isolation of anti-toxin single domain antibodies from a semi-synthetic spiny dogfish shark display library. BMC Biotechnol. 2007, 7, 78.

27. Fellouse, F.A.; Li, B.; Compaan, D.M.; Peden, A.A.; Hymowitz, S.G.; Sidhu, S.S. Molecular recognition by a binary code. J. Mol. Biol. 2005, 348, 1153-1162.

28. Mondon, P.; Souyris, N.; Douchy, L.; Crozet, F.; Bouayadi, K.; Kharrat, H. Method for generation of human hyperdiversified antibody fragment library. J. Biotechnol. 2007, 2, 76-82.

29. Qin, W.; Zhao, A.; Han, Y.; Wen, W.; Li, Y.; Chen, G.; Zhang, Z.; Wang, H. A novel technique for efficient construction of large scFv libraries. Mol. Biotechnol. 2007, 37, 201-205.

30. Verheesen, P.; Roussis, A.; de Haard, H.J.; Groot, A.J.; Stam, J.C.; den Dunnen, J.T.; Frants, R.R.; Verkleij, A.J.; Theo Verrips, C.; van der Maarel, S.M. Reliable and controllable antibody fragment selections from Camelid non-immune libraries for target validation. Biochim. Biophys. Acta. 2006, 1764, 1307-1319.

31. Conrath, K.E.; Lauwereys, M.; Galleni, M.; Matagne, A.; Frere, J.M.; Kinne, J.; Wyns, L.; Muyldermans, S. Beta-lactamase inhibitors derived from single-domain antibody fragments elicited in the camelidae. Antimicrob. Agents Chemother. 2001, 45, 2807-2812.

32. Dolk, E.; van der Vaart, M.; Lutje Hulsik, D.; Vriend, G.; de Haard, H.; Spinelli, S.; Cambillau, C.; Frenken, L.; Verrips, T. Isolation of llama antibody fragments for prevention of dandruff by phage display in shampoo. Appl. Environ. Microbiol. 2005, 71, 442-450.

33. Saerens, D.; Kinne, J.; Bosmans, E.; Wernery, U.; Muyldermans, S.; Conrath, K. Single domain antibodies derived from dromedary lymph node and peripheral blood lymphocytes sensing conformational variants of prostate-specific antigen. J. Biol. Chem. 2004, 279, 51965-51972.

34. Azzazy, H.M.; Highsmith, W.E., Jr. Phage display technology: clinical applications and recent innovations. Clin. Biochem. 2002, 35, 425-445.

35. Liu, B.; Huang, L.; Sihlbom, C.; Burlingame, A.; Marks, J.D. Towards proteome-wide production of monoclonal antibody by phage display. J. Mol. Biol. 2002, 315, 1063-1073.

36. Smith, G.P.; Petrenko, V.A. Phage Display. Chem. Rev. 1997, 97, 391-410.

37. He, M.; Taussig, M.J. Rapid discovery of protein interactions by cell-free protein technologies. Biochem. Soc. Trans. 2007, 35, 962-965.

38. Schaffitzel, C.; Hanes, J.; Jermutus, L.; Pluckthun, A. Ribosome display: an in vitro method for selection and evolution of antibodies from libraries. J. Immunol. Methods 1999, 231, 119-135.

39. Wang, M.; He, M. The rapid discovery of engineered antibodies. IDrugs 2007, 10, 562-565.

40. Zahnd, C.; Amstutz, P.; Pluckthun, A. Ribosome display: selecting and evolving proteins in vitro that specifically bind to a target. Nat. Methods 2007, 4, 269-279. 
41. Kopsidas, G.; Carman, R.K.; Stutt, E.L.; Raicevic, A.; Roberts, A.S.; Siomos, M.A.; Dobric, N.; Pontes-Braz, L.; Coia, G. RNA mutagenesis yields highly diverse mRNA libraries for in vitro protein evolution. BMC Biotechnol. 2007, 7, 18.

42. Adamson, C.S.; Yao, Y.; Vasiljevic, S.; Sy, M.S.; Ren, J.; Jones, I.M. Novel single chain antibodies to the prion protein identified by phage display. Virology 2007, 358, 166-177.

43. Oh, M.Y.; Joo, H.Y.; Hur, B.U.; Jeong, Y.H.; Cha, S.H. Enhancing phage display of antibody fragments using gIII-amber suppression. Gene 2007, 386, 81-89.

44. Steinhauer, C.; Wingren, C.; Hager, A.C.; Borrebaeck, C.A. Single framework recombinant antibody fragments designed for protein chip applications. Biotechniques 2002, Suppl, 38-45.

45. Jespers, L.; Schon, O.; Famm, K.; Winter, G. Aggregation-resistant domain antibodies selected on phage by heat denaturation. Nat. Biotechnol. 2004, 22, 1161-1165.

46. Yan, X.H.; Xu, Z.R. Production of human single-chain variable fragment (scFv) antibody specific for digoxin by ribosome display. Indian J. Biochem. Biophys. 2005, 42, 350-357.

47. Backmann, N.; Zahnd, C.; Huber, F.; Bietsch, A.; Pluckthun, A.; Lang, H.P.; Guntherodt, H.J.; Hegner, M.; Gerber, C. A label-free immunosensor array using single-chain antibody fragments. Proc. Natl. Acad. Sci. U S A 2005, 102, 14587-14592.

48. Harrison, J.S.; Gill, A.; Hoare, M. Stability of a single-chain Fv antibody fragment when exposed to a high shear environment combined with air-liquid interfaces. Biotechnol. Bioeng. 1998, 59, 517-519.

49. Arndt, K.M.; Muller, K.M.; Pluckthun, A. Helix-stabilized Fv (hsFv) antibody fragments: substituting the constant domains of a Fab fragment for a heterodimeric coiled-coil domain. $J$. Mol. Biol. 2001, 312, 221-228.

50. Webber, K.O.; Reiter, Y.; Brinkmann, U.; Kreitman, R.; Pastan, I. Preparation and characterization of a disulfide-stabilized Fv fragment of the anti-Tac antibody: comparison with its single-chain analog. Mol. Immunol. 1995, 32, 249-258.

51. Young, N.M.; MacKenzie, C.R.; Narang, S.A.; Oomen, R.P.; Baenziger, J.E. Thermal stabilization of a single-chain Fv antibody fragment by introduction of a disulphide bond. FEBS Lett. 1995, 377, 135-139.

52. Quintero-Hernandez, V.; Juarez-Gonzalez, V.R.; Ortiz-Leon, M.; Sanchez, R.; Possani, L.D.; Becerril, B. The change of the scFv into the Fab format improves the stability and in vivo toxin neutralization capacity of recombinant antibodies. Mol. Immunol. 2007, 44, 1307-1315.

53. Monsellier, E.; Bedouelle, H. Quantitative measurement of protein stability from unfolding equilibria monitored with the fluorescence maximum wavelength. Protein Eng. Des. Sel. 2005, $18,445-456$.

54. Jung, S.; Pluckthun, A. Improving in vivo folding and stability of a single-chain Fv antibody fragment by loop grafting. Protein Eng. 1997, 10, 959-966.

55. Krauss, J.; Arndt, M.A.; Martin, A.C.; Liu, H.; Rybak, S.M. Specificity grafting of human antibody frameworks selected from a phage display library: generation of a highly stable humanized anti-CD22 single-chain Fv fragment. Protein Eng. 2003, 16, 753-759.

56. Saerens, D.; Pellis, M.; Loris, R.; Pardon, E.; Dumoulin, M.; Matagne, A.; Wyns, L.; Muyldermans, S.; Conrath, K. Identification of a Universal VHH Framework to Graft Non- 
canonical Antigen-binding Loops of Camel Single-domain Antibodies. J. Mol. Biol. 2005, 352, 597-607.

57. Saerens, D.; Conrath, K.; Govaert, J.; Muyldermans, S. Disulfide bond introduction for general stabilization of immunoglobulin heavy-chain variable domains. J. Mol. Biol. 2008, 377, 478-488.

58. Hagihara, Y.; Mine, S.; Uegaki, K. Stabilization of an immunoglobulin fold domain by an engineered disulfide bond at the buried hydrophobic region. J. Biol. Chem. 2007, 282, 3648936495.

59. Harmsen, M.M.; van Solt, C.B.; van Zijderveld-van Bemmel, A.M.; Niewold, T.A.; van Zijderveld, F.G. Selection and optimization of proteolytically stable llama single-domain antibody fragments for oral immunotherapy. Appl. Microbiol. Biotechnol. 2006, 72, 544-551.

60. Jung, S.; Honegger, A.; Pluckthun, A. Selection for improved protein stability by phage display. J. Mol. Biol. 1999, 294, 163-180.

61. van der Linden, R.H.; de Geus, B.; Frenken, G.J.; Peters, H.; Verrips, C.T. Improved production and function of llama heavy chain antibody fragments by molecular evolution. J. Biotechnol. 2000, 80, 261-270.

62. Saerens, D.; Frederix, F.; Reekmans, G.; Conrath, K.; Jans, K.; Brys, L.; Huang, L.; Bosmans, E.; Maes, G.; Borghs, G.; Muyldermans, S. Engineering Camel Single-Domain Antibodies and Immobilization Chemistry for Human Prostate-Specific Antigen Sensing. Anal. Chem. 2005, 77, 7547-7555.

63. Cao, T.; Wang, A.; Liang, X.; Tang, H.; Auner, G.W.; Salley, S.O.; Ng, K.Y. Investigation of spacer length effect on immobilized Escherichia coli pili-antibody molecular recognition by AFM. Biotechnol. Bioeng. 2007, 98, 1109-1122.

64. Huang, L.; Reekmans, G.; Saerens, D.; Friedt, J.M.; Frederix, F.; Francis, L.; Muyldermans, S.; Campitelli, A.; Hoof, C.V. Prostate-specific antigen immunosensing based on mixed selfassembled monolayers, camel antibodies and colloidal gold enhanced sandwich assays. Biosens. Bioelectron. 2005, 21, 483-490.

65. Norde, W. Adsorption of proteins from solution at the solid-liquid interface. Adv. Colloid. Interface Sci. 1986, 25, 267-340.

66. Oh, B.K.; Kim, Y.K.; Lee, W.; Bae, Y.M.; Lee, W.H.; Choi, J.W. Immunosensor for detection of Legionella pneumophila using surface plasmon resonance. Biosens. Bioelectron. 2003, 18, 605611.

67. Boltovets, P.M.; Boyko, V.R.; Kostikov, I.Y.; Dyachenko, N.S.; Snopok, B.A.; Shirshov, Y.M. Simple method for plant virus detection: effect of antibody immobilization technique. $J$. Virol. Methods 2002, 105, 141-146.

68. Bonroy, K.; Frederix, F.; Reekmans, G.; Dewolf, E.; De Palma, R.; Borghs, G.; Declerck, P.; Goddeeris, B. Comparison of random and oriented immobilisation of antibody fragments on mixed self-assembled monolayers. J. Immunol. Methods 2006, 312, 167-81.

69. Ionescu, R.E.; Jaffrezic-Renault, N.; Bouffier, L.; Gondran, C.; Cosnier, S.; Pinacho, D.G.; Marco, M.P.; Sanchez-Baeza, F.J.; Healy, T.; Martelet, C. Impedimetric immunosensor for the specific label free detection of ciprofloxacin antibiotic. Biosens. Bioelectron. 2007, 23, 549-555. 
70. Sun, Y.; Bai, Y.; Song, D.; Li, X.; Wang, L.; Zhang, H. 2007 Design and performances of immunoassay based on SPR biosensor with magnetic microbeads. Biosens. Bioelectron. 2007, 23, 473-478.

71. Lee, W.; Oh, B.K.; Lee, W.H.; Choi, J.W. Immobilization of antibody fragment for immunosensor application based on surface plasmon resonance. Colloids. Surf. B Biointerfaces 2005, 40, 143 148.

72. Torrance, L.; Ziegler, A.; Pittman, H.; Paterson, M.; Toth, R.; Eggleston, I. Oriented immobilisation of engineered single-chain antibodies to develop biosensors for virus detection. $J$. Virol. Methods 2006, 134, 164-170.

73. Lee, K.G.; Pillai, S.R.; Singh, S.R.; Willing, G.A. The investigation of Protein A and Salmonella antibody adsorption onto biosensor surfaces by atomic force microscopy. Biotechnol. Bioeng. 2007, 99(4), 949-959

74. Shen, Z.; Yan, H.; Parl, F.F.; Mernaugh, R.L.; Zeng, X. Recombinant antibody piezoimmunosensors for the detection of cytochrome P450 1B1. Anal. Chem. 2007, 79, 1283 1289.

75. Cho, I.H., Paek, E.H., Lee, H., Kang, J.Y., Kim, T.S.; Paek, S.H. Site-directed biotinylation of antibodies for controlled immobilization on solid surfaces. Anal. Biochem. 2007, 365, 14-23.

76. Scholler, N.; Garvik, B.; Quarles, T.; Jiang, S.; Urban, N. Method for generation of in vivo biotinylated recombinant antibodies by yeast mating. J. Immunol. Methods 2006, 317, 132-143.

77. Pleschberger, M.; Saerens, D.; Weigert, S.; Sleytr, U.B.; Muyldermans, S.; Sara, M.; Egelseer, E.M. An S-layer heavy chain camel antibody fusion protein for generation of a nanopatterned sensing layer to detect the prostate-specific antigen by surface plasmon resonance technology. Bioconjug. Chem. 2004, 15, 664-671.

78. Nanduri, V.; Bhunia, A.K.; Tu, S.I.; Paoli, G.C.; Brewster, J.D. SPR biosensor for the detection of L. monocytogenes using phage-displayed antibody. Biosens. Bioelectron. 2007, 23, 248-252.

79. Gilchuk, P.V.; Volkov, G.L. Immobilization of mouse single-chain antibodies for affinity chromatography using the cellulose-binding protein. Ukr Biokhim Zh. 2006, 78, 160-163.

80. Shen, Z.; Mernaugh, R.L.; Yan, H.; Yu, L.; Zhang, Y.; Zeng, X. Engineered recombinant singlechain fragment variable antibody for immunosensors. Anal. Chem. 2005, 77, 6834-6842.

81. Steinhauer, C.; Wingren, C.; Khan, F.; He, M.; Taussig, M.J.; Borrebaeck, C.A. Improved affinity coupling for antibody microarrays: engineering of double-(His)6-tagged single framework recombinant antibody fragments. Proteomics 2006, 6, 4227-4234.

82. Watanabe, H.; Tsumoto, K.; Taguchi, S.; Yamashita, K.; Doi, Y.; Nishimiya, Y.; Kondo, H.; Umetsu, M.; Kumagai, I. A human antibody fragment with high affinity for biodegradable polymer film. Bioconjug. Chem. 2007, 18, 645-651.

83. Hattori, T.; Umetsu, M.; Nakanishi, T.; Tsumoto, K.; Ohara, S.; Abe, H.; Naito, M.; Asano, R.; Adschiri, T.; Kumagai, I. Grafting of material-binding function into antibodies Functionalization by peptide grafting. Biochem. Biophys. Res. Commun. 2008, 365, 751-757.

84. Mechaly, A.; Zahavy, E.; Fisher, M. Development and implementation of a scFv antibody for specific detection of B. anthracis spores. Appl. Environ. Microbiol. 2007, 74 (3), 818-822. 
85. Hu, X.; O'Hara, L.; White, S.; Magner, E.; Kane, M.; Wall, J.G. Optimisation of production of a domoic acid-binding scFv antibody fragment in Escherichia coli using molecular chaperones and functional immobilisation on a mesoporous silicate support. Protein. Expr. Purif. 2007, 52, 194201.

86. Deng, X.K.; Nesbit, L.A.; Morrow, K.J., Jr. Recombinant single-chain variable fragment antibodies directed against Clostridium difficile toxin B produced by use of an optimized phage display system. Clin. Diagn. Lab. Immunol. 2003, 10, 587-595.

87. Carlsson, A.; Wingren, C.; Ingvarsson, J.; Ellmark, P.; Baldertorp, B.; Ferno, M.; Olsson, H.; Borrebaeck, C.A. Serum proteome profiling of metastatic breast cancer using recombinant antibody microarrays. Eur. J. Cancer. 2007, 44(3), 472-480.

88. Ymeti, A.; Subramaniam, V.; Beumer, T.A.; Kanger, J.S. An ultrasensitive young interferometer handheld sensor for rapid virus detection. Expert Rev. Med. Devices 2007, 4, 447-454.

(C) 2008 by the authors; licensee Molecular Diversity Preservation International, Basel, Switzerland. This article is an open-access article distributed under the terms and conditions of the Creative Commons Attribution license (http://creativecommons.org/licenses/by/3.0/). 